\title{
Deep seismic activities preceding the three large 'shallow' earthquakes off south-east Hokkaido, Japan—the 2003 Tokachi-oki earthquake, the 1993 Kushiro-oki earthquake and the 1952 Tokachi-oki earthquake
}

\author{
Kiyoo Mogi \\ University of Tokyo, Japan \\ (Received December 8, 2003; Revised February 25, 2004; Accepted February 25, 2004)
}

\begin{abstract}
The 2003 Tokachi-oki earthquake of M 8.0, which occurred off the south-east coast of Hokkaido, Japan, was preceded by noticeable deep seismicity in the subducting slab, including a deep-focus earthquake of M 7.1. The 1952 Tokachi-oki earthquake of M 8.2 and the 1993 Kushiro-oki earthquake of M 7.5, which occurred also off the south-east of Hokkaido along the Kurile Trench, were also preceded by high deep seismicity including large deepfocus earthquakes of the M 7 or over (focal depths 200-600 km). The relations between the deep seismicity and the 'shallow' large earthquake (focal depth $\leq 100 \mathrm{~km}$ ) in these three cases are quite similar. This result strongly supports the author's view (Mogi, 1973, 1988) that large 'shallow' earthquakes along the subduction zones are sometimes preceded by the occurrence of large deep-focus earthquakes.
\end{abstract}

Key words: Tokachi-oki, Kushiro-oki, deep-focus foreshocks, downward migration, subducting slab, trigger.

\section{Introduction}

In a previous paper (Mogi, 1973), the author reported several instances in which great shallow earthquakes along the Kurile-Japan Trench were preceded by the occurrence of noticeable deep seismic activity including large deep-focus earthquakes of the M 7 class. According to the result, large shallow earthquakes of different types occurred, for example, the 1933 Sanriku-oki earthquake (M 8.3) of the intra-plate type and the 1952 Tokachi-oki earthquake (M 8.2) of the inter-plate type. The gradual downward migration of seismic activity in the subducting slab before the high deep seismic activity was pointed out in some regions (Mogi, 1973, 1988). These results have been obtained for different places and by use of the old version of the Japan Meteorological Agency (JMA) Catalogue. In this paper, the recently revised JMA Catalogue (2003) is used. However, the previously obtained main results do not change using of the revised version of JMA Catalogue.

On September 26, 2003, a great shallow earthquake of M 8.0 occurred off the south-east coast of Hokkaido. This earthquake was a low-angle, thrust-type, inter-plate earthquake which occurred on the upper surface of the Pacific Plate subducting beneath Hokkaido. The location, the focal mechanism and the magnitude of this earthquake are quite similar to those of the 1952 Tokachi-oki earthquake of M 8.2. In the case of the 1952 Tokachi-oki earthquake, a marked deep seismic activity including a large deep-focus earthquake of M 7.5 was observed before the earthquake.

In addition, on January 15, 1993, the 1993 Kushiro-oki earthquake of M 7.5 occurred at a depth of $100 \mathrm{~km}$ in the ad-

Copy right(c) The Society of Geomagnetism and Earth, Planetary and Space Science (SGEPSS); The Seismological Society of Japan; The Volcanological Society of Japan; The Geodetic Society of Japan; The Japanese Society for Planetary Sciences; TERRAPUB jacent region. According to the observations by JMA (1993) and the Hokkaido University (1993), this was an intra-plate earthquake, which occurred within the Pacific Plate subducting beneath Hokkaido from the Kurile Trench. According to the aftershock distribution and the focal mechanism analysis, the fault plane of this earthquake was nearly horizontal and the lower surface of the fault slipped northward (JMA, 1993; Kasahara, 2000) (see Fig. 7).

These successive occurrences of the three large 'shallow' earthquakes in nearly the same region may provide a very rare chance to examine the relation between the deep seismic activity and the large shallow earthquake which was reported thirty years ago.

\section{Distribution of Shallow Large Earthquakes and Deep-focus Earthquakes}

In Fig.1, the focal regions of the 2003 Tokachi-oki earthquake, the 1952 Tokachi-oki earthquake and the 1993 Kushiro-oki earthquake are shown, and the largest deepfocus earthquakes prior to these large shallow earthquakes are indicated by solid circles. Broken curves and numerals show depths of the subducing slab obtained from the distribution of the deep-focus earthquakes.

This figure illustrates that these three large shallow earthquakes occurred along the western part of the Kurile Trench, connected to the Japanese Trench, and that the deep seismic activities are markedly high near this area. In this paper, seismic activities in the rectangular region indicated in this figure are discussed.

In Fig. 2(a), (b) and (c), the focal regions of the large shallow earthquakes and the deep-focus earthquakes $(\mathrm{M} \geq$ 5.0 , focal depth $\geq 200 \mathrm{~km}$ ) preceding the large shallow earthquakes are shown in the cases of the 2003 Tokachi-oki earthquake, the 1952 Tokachi-oki earthquake and the 1993 


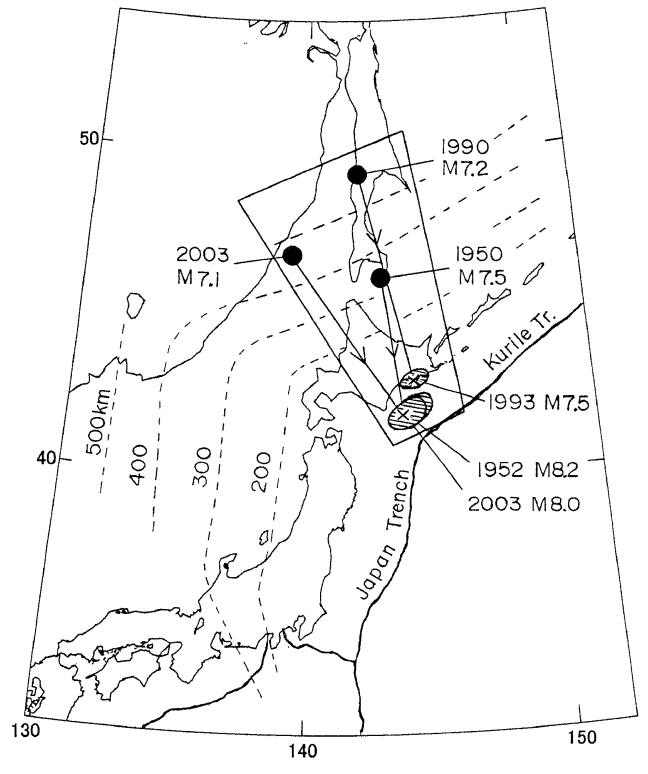

Fig. 1. Locations of the focal regions of the 2003 Tokachi-oki earthquake, the 1952 Tokachi-oki earthquake and the 1993 Kushiro-oki earthquake, and the largest deep-focus earthquakes prior to these large shallow earthquakes.

Kushiro-oki earthquake, respectively. The seismic activity in the subducting slab shown by a rectangular area is discussed. Numerals near circular symbols indicate the year of earthquake occurrence and solid curves and numerals mark depths of the deep seismic plane or the subducting slab. In these figures, deep-focus earthquakes just before the large shallow earthquakes are indicated by solid circles. From these figures, the increase in the deep seismic activity preceding the large shallow earthquake can be observed in these three cases.
Figure 3 displays the M-T graph of the deep-focus (depth $\geq 200 \mathrm{~km}$ ) earthquakes which occurred in the abovementioned region from 1978 to 2003. In this period the 1993 Kushiro-oki earthquake and the 2003 Tokachi-oki earthquake occurred in the adjacent region (in the same area in the wide sense). The deep seismic activity in this region gradually increased before the Kushiro-oki earthquake. The largest deep-focus earthquake of M 7.2 occurred on May 12, 1990 beneath the central Sakhalin. Y. Motoya and Mogi discussed the possibility of the occurrence of a large shallow earthquake along the Kurile Trench, because the 1952 Tokachi-oki earthquake was preceded by a large deep-focus earthquake as mentioned above. Actually the 1993 Kushirooki earthquake of M 7.5 and of focal depth $100 \mathrm{~km}$, which is an intra-plate earthquake, occurred.

After the 1993 Kushiro-oki earthquake, the deep seismic activity decreased rapidly. However, it began to increase from 2000 and a large deep-focus earthquake of M 7.1 occurred on July 27, 2003, and the 2003 Tokachi-oki earthquake occurred on September 26, 2003.

\section{Temporal Variation of Focal Depths of Deep- focus Earthquakes}

Figure 4 shows the temporal variation of the focal depths of earthquakes in and around the region of the 1952 Tokachioki earthquake (M 8.2). This figure is reproduced from a previous paper (Mogi, 1988). The diagram on the right-hand side of Fig. 4 plots the earthquakes in the region, shown in the left diagram, with the vertical axis denoting the focal depth and the horizontal axis denoting time. An examination of this figure makes it clear that the deep seismic activity in this region was very active one or two years before the 1952 Tokachi-oki earthquake, as mentioned before. Shallow seismic activity was considerably high about ten years before the 1952 Tokachi-oki earthquake, and this activity showed a ten-
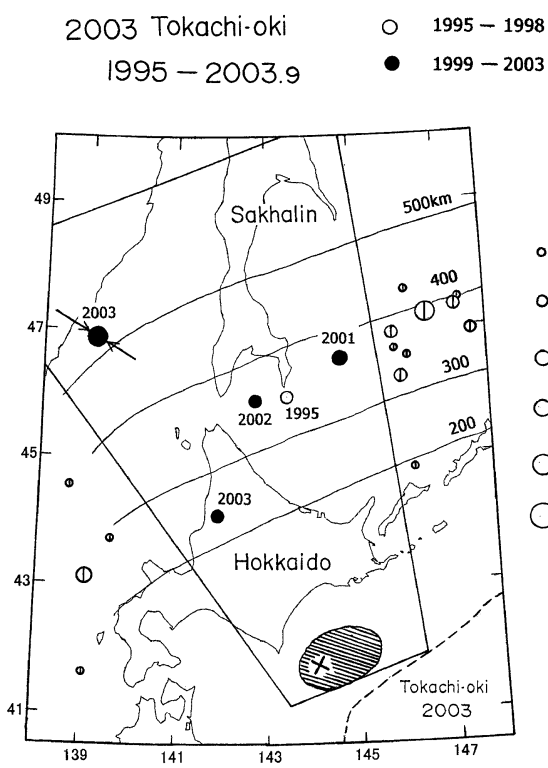

(a)

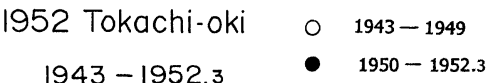

1993 Kushiro-oki

$1980-1993.1$

$1980-1986$

- $1987-1993$
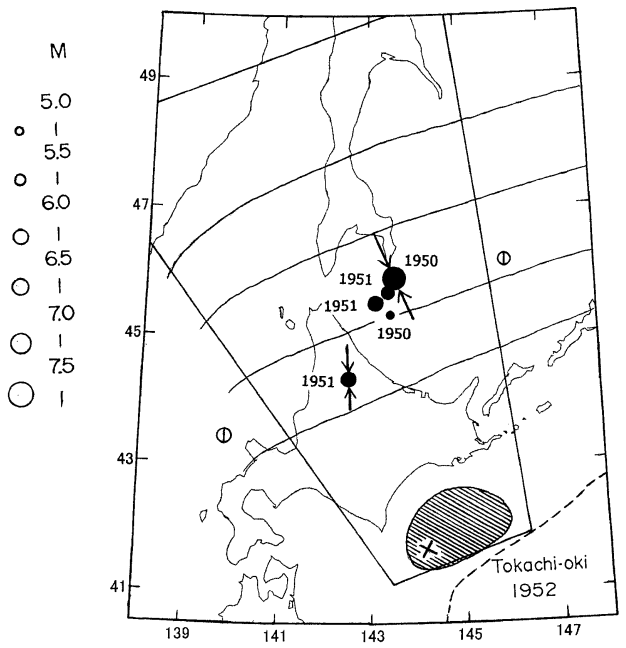

(b)

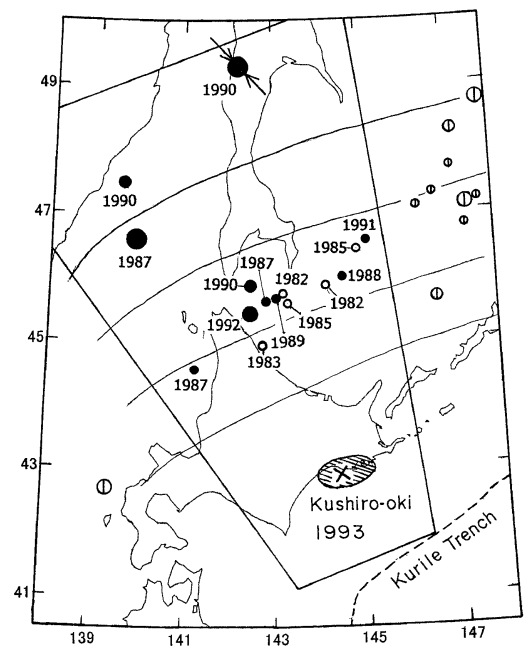

(c)

Fig. 2. (a) Locations of the 2003 Tokachi-oki earthquake and deep-focus earthquakes $(\mathrm{M} \geq 5.0$, focal depth $\geq 200 \mathrm{~km})$ preceding the large shallow earthquake. (b) and (c) Locations of the 1952 Tokachi-oki earthquake and the 1993 Kushiro-oki earthquake and deep-focus earthquakes (M $\geq 5.0$, focal depth $\geq 200 \mathrm{~km}$ ) preceding these large shallow earthquakes, respectively. 


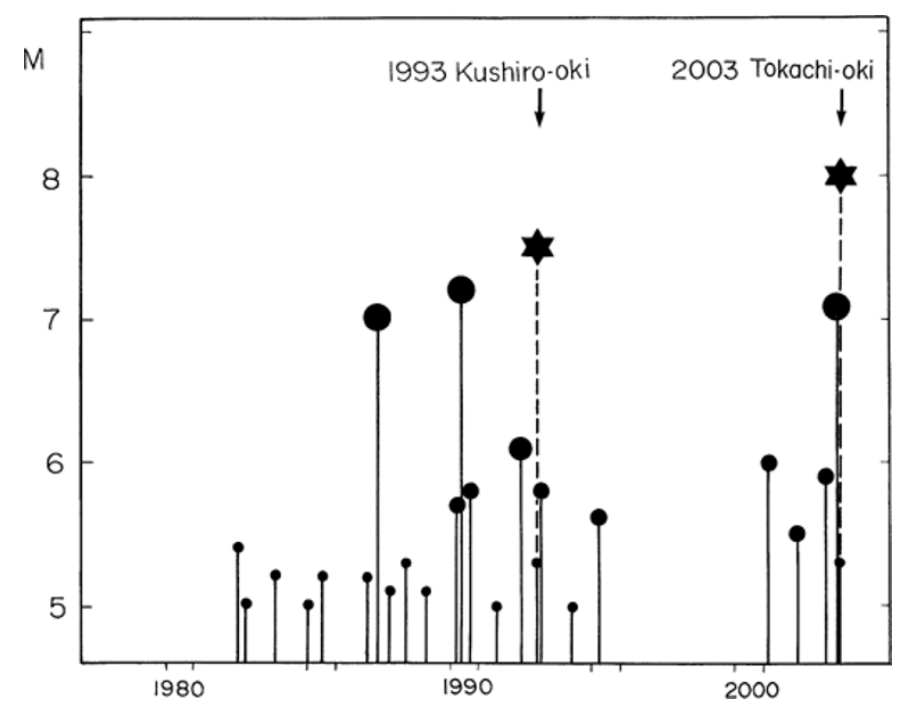

Fig. 3. M-T graph of the deep-focus earthquakes $(M \geq 5.0$, focal depth $\geq 200 \mathrm{~km})$ which occurred in the rectangular region shown in Fig. 2 from 1978 to 2003 (solid circles) and that of the 1993 Kushiro-oki earthquake and the 2003 Tokachi-oki earthquake (solid stars symbols).

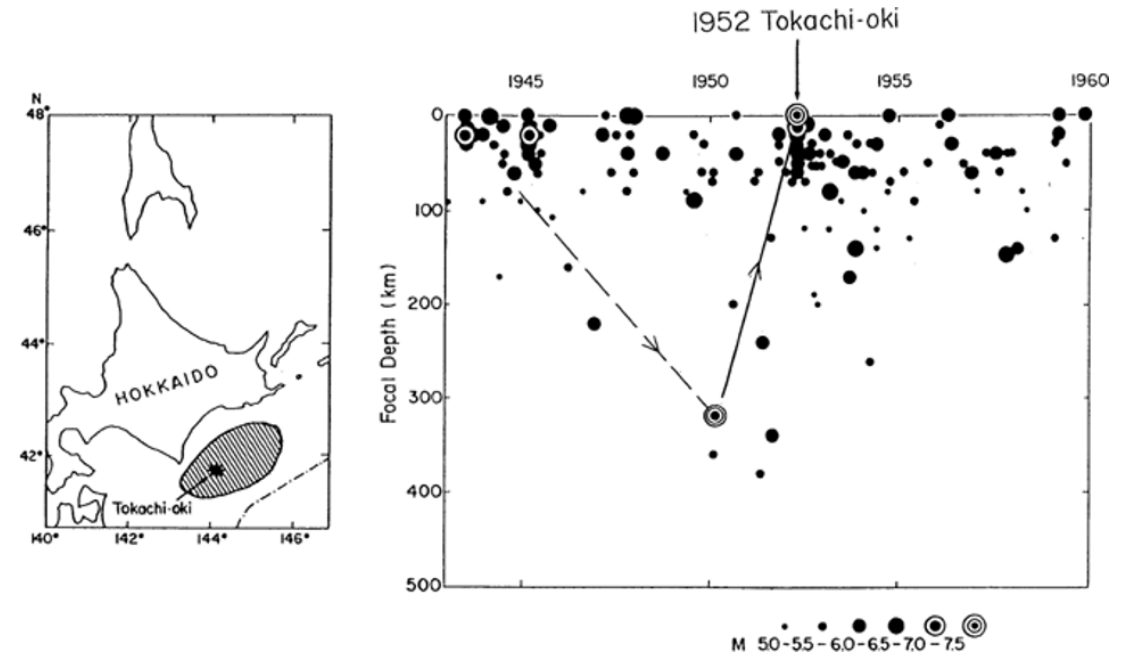

Fig. 4. Focal depths of earthquakes before and after the 1952 Tokachi-oki earthquake in the area shown in the left figure are plotted against time (Mogi, 1988).

$$
1978-2003 \quad M \geq 5.0 \quad \text { Depth } 2100 \mathrm{~km}
$$

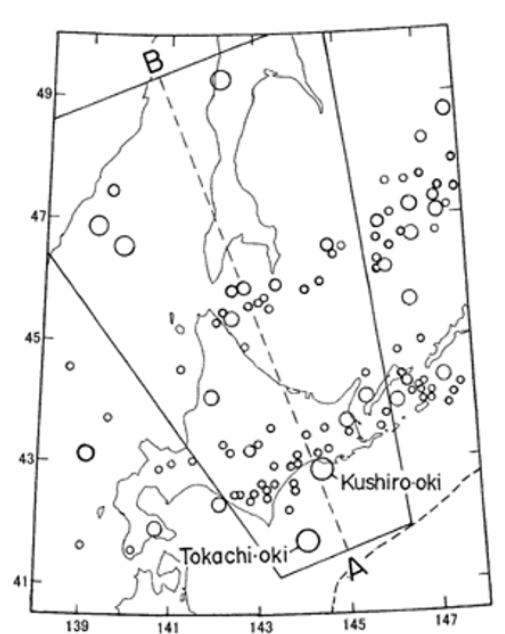

(a)

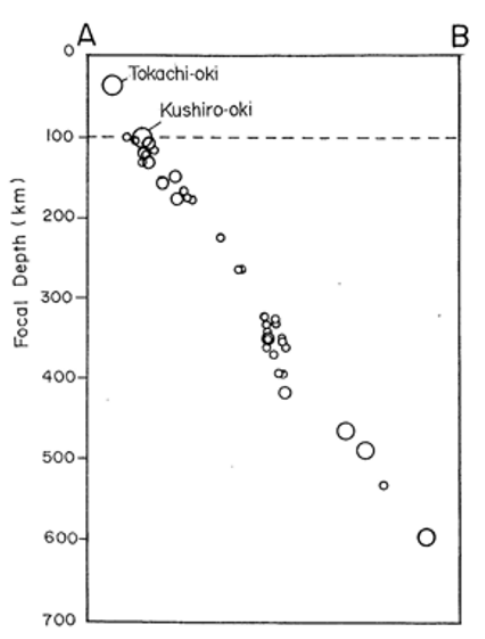

(b)

Fig. 5. (a) Locations of earthquakes which occurred from 1978 to 2003 . in and around Hokkaido ( $\mathrm{M} \geq 5.0$, focal depth $\geq 100 \mathrm{~km}$ ) and the 2003 Tokachi-oki earthquake and the 1993 Kushiro-oki earthquake. (b) Vertical projection of earthquakes in the rectangular region in (a) along AB line. 


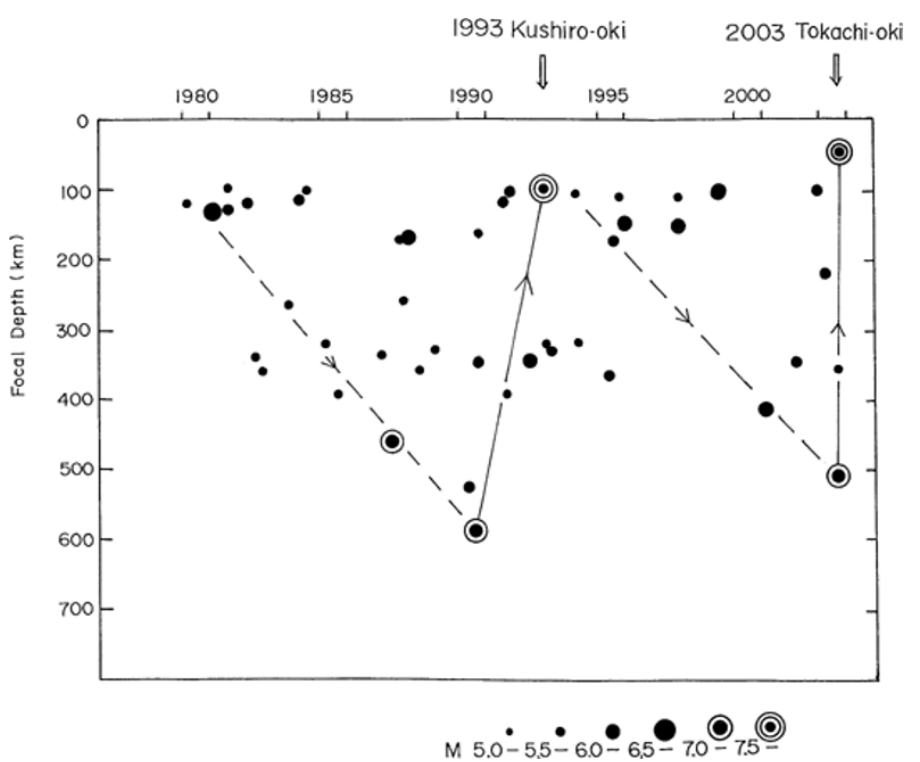

Fig. 6. Focal depths of earthquakes in the rectangular region shown in Fig. 5(a) are plotted against time.

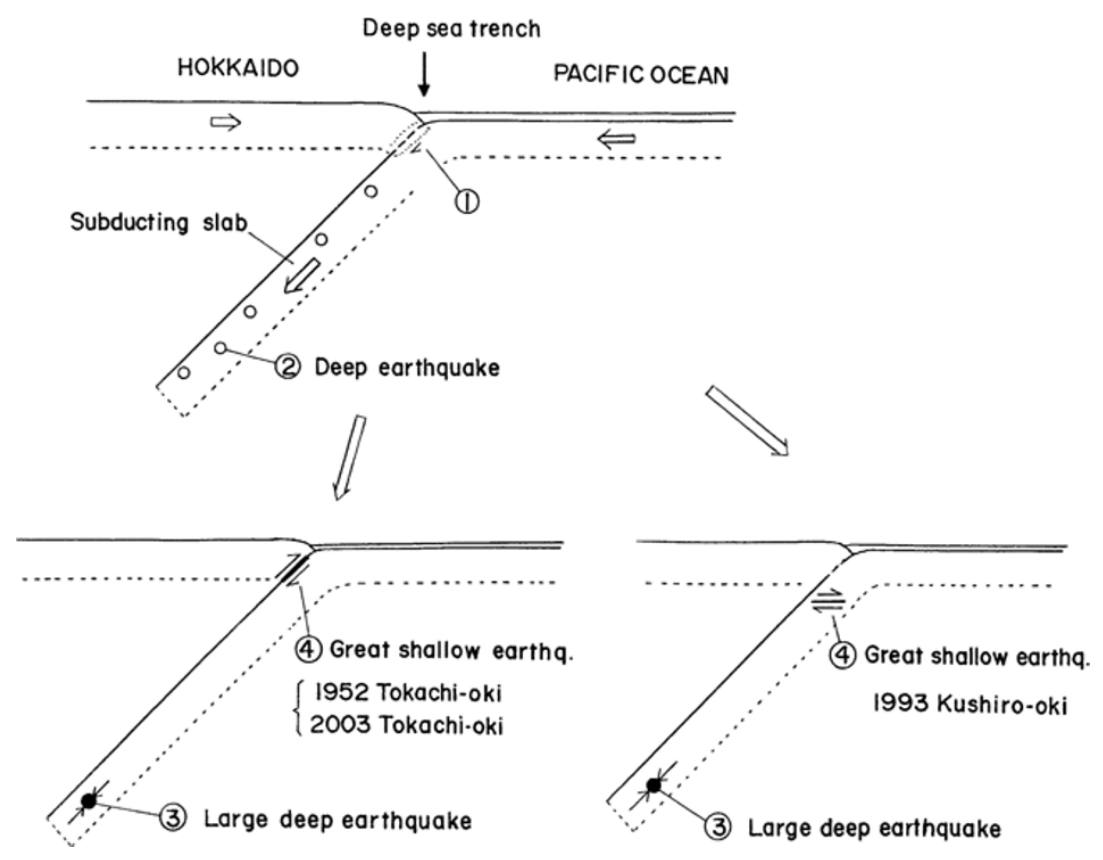

Fig. 7. Diagram illustrating schematically the mechanism of the occurrence of large shallow earthquakes and their relation to the deep seismic activity. Both the cases of the inter-plate earthquake (left) and the intra-plate earthquake (right) are shown. The processes (1), (2), (3) and (4) successively occur.

dency to migrate downwards gradually. Deep seismic activity commenced subsequent to this downward migration, including a large earthquake in 1950 (M 7.5, depth of $343 \mathrm{~km}$ ). Thus, seismic activity migrated downward and a large deepfocus earthquake occurred when it reaches at some depth, and it was followed shortly afterward by a great shallow earthquake. In Fig. 4, the broken line indicates the downward migration and the thick line indicates the rapid upward migration from the largest deep-focus earthquake to the great shallow earthquake.

To examine whether or not the above-mentioned result obtained in the case of the 1952 Tokachi-oki earthquake is accidental or not, recent data on the deep seismic activity are quite useful. Figures 5 and 6 show the result of this examination. The left diagram of Fig. 5 shows the locations of major earthquakes $(M \geq 5.0$, focal depth $\geq 100 \mathrm{~km})$ which occurred during the period (1978-2003) in this region. The seismic activity in the rectangular region as shown in the left figure is discussed below. The right diagram shows the vertical projection along the $\mathrm{AB}$ line. The seismic activity in the subducting slab can be recognized clearly.

Figure 6 shows the temporal variation of focal depths of earthquakes $(M \geq 5.0$, focal depth $\geq 100 \mathrm{~km})$ and the 2003 Tokachi-oki earthquake of M 8.0 in this region. The vertical axis denotes the focal depth and the horizontal axis denotes time. In this figure, the two phases can be clearly distin- 
guished. One is related to the 1993 Kushiro-oki earthquake and the other is the process related to the 2003 Tokachi-oki earthquake. It is noteworthy that the gradual downward migration of seismic activity, the occurrence of the largest deepfocus earthquake, the rapid upward migration of seismic activity and the occurrence of the large shallow earthquake can be seen in these two processes. This pattern of deep seismic activity prior to a large shallow earthquake is quite similar to that in the case of the 1952 Tokachi-oki earthquake, mentioned above. Thus, it is concluded that the above-mentioned process observed before the 1952 Tokachi-oki earthquake is not accidental, but it is common in the three large shallow earthquakes which occurred successively off the south-east coast of Hokkaido.

\section{Discussion}

According to the above-mentioned results, seismic activity migrates gradually downward along the subducting slab. When this downward migration of seismic activity reaches some depth, large deep-focus earthquakes of down-dip compression type occur in the subducting slab, and the deep part of the slab is shortened in the direction of subduction. This shortening of the deep part of the slab should accelerate the subduction of the shallow part of the slab. Thus, the interplate type great shallow earthquake occurred in the Tokachioki region in 1952, and again in 2003.

In the Kushiro-oki region adjacent to the Tokachi-oki region, the shortening of the deep part of the subducting slab, producing a tensile stress in the shallow portion of the slab, caused the intra-plate large earthquake of the down-dip extension type. These deep-focus large earthquakes occurred at distant regions of the subducting slab, but they probably triggered the occurrence of large shallow earthquakes along the deep sea trench. Therefore, they are described as "deepfocus foreshocks" (Mogi, 1985).

Figure 7 shows the diagram illustrating schematically the mechanism of the occurrence of large shallow earthquakes in the subduction zone and their relation to the deep seismic activity. The cases of the inter-plate earthquake and the intraplate earthquake are elucidated by the schematic figure.

Other examples of deep-focus foreshocks are reported in a previous paper (Mogi, 1973). As already mentioned, large shallow earthquakes in the subduction zone are not always preceded by deep-focus foreshocks. Generally speaking, large shallow earthquakes near the connection region of two deep sea trenches are preceded by deep-focus foreshocks with high probability. Since deep-focus foreshocks occur months or 1-2 years before large shallow earthquakes, they may be useful for intermediate-term earthquake prediction.

\section{Conclusion}

(1) The 2003 Tokachi-oki earthquake and the 1993 Kushiro-oki earthquake were preceded by noticeable deep seismic activity; that is, deep-focus foreshocks were observed.

(2) A close relation between the deep seismicity and the large 'shallow' earthquakes which occurred in the subduction zone, reported in the previous papers, is not accidental, but it is common in all three large 'shallow' earthquakes which occurred off the south-east coast of Hokkaido in the past several tens years.

The following seismic process-(1) downward migration of seismic activity from shallow to deep region along the subducting slab, (2) occurrence of a large deep-focus earthquake of M 7 class, (3) rapid upward migration, (4) occurrence of a large shallow earthquake-was observed in these three great events.

Acknowledgments. I would like to thank the Japan Meteorological Agency providing us data from the JMA Catalogue (2003). I am also grateful to Y. Ishikawa and an anonymous reviewer for their helpful comments.

\section{References}

Hokkaido University, 1993 Kushiro-oki earthquake (1), Rep. Coord. Comm. Earthq. Predict., 50, 17-22, 1993 (in Japanese).

Japan Meteorological Agency (JMA), The kushiro-oki earthquake, 1993 (January 15, M 7.8), Rep. Coord. Comm. Earthq. Predict., 50, 8-16, 1993 (in Japanese).

Kasahara, M., 1993 Kushiro-oki earthquake, in The Course of 30 years of the Coordinating Committee for Earthquake Prediction, 149-159, 2000 (in Japanese).

Mogi, K., Relationship between shallow and deep seismicity in the western Pacific region, Tectonophysics, 17, 1-22, 1973.

Mogi, K., Earthquake Prediction, 355 pp. Academic Press, Tokyo, 1985

Mogi, K., Downward migration of seismic activity prior to some great shallow earthquakes in Japanese subduction zone-A possible intermediateterm precursor, PAGEOF, 126, 447-463, 1988. 